\title{
ANALISIS SIKAP DAN PERILAKU KONSUMEN TERHADAP PRODUK DONAT PAKET SURYA BAKERY DI KOTA BENGKULU
}

\author{
CONSUMERS' ATTITUDE AND BEHAVIOUR TOWARD DONUT \\ PRODUCT OF SURYA BAKERY IN BENGKULU CITY
}

\author{
Dwita Frisdinawati, dan Basuki Sigit Priyono \\ Jurusan Sosial Ekonomi Pertanian Fakultas Pertanian Universitas Bengkulu
}

\begin{abstract}
One form of agro-processing industry is donuts. The bakery is one business that is engaged in the fulfillment of their needs and as a tangible example of product development of agricultural products, which also had a very tight competition from time to time. The research was conducted in February-March 2012 in the city of Bengkulu with the aim of knowing the attitudes and behavior of consumers towards the product package Surya donut bakery in the city of Bengkulu. Overall the total consumer attitude $(A B)$ to the product package Surya donut bakery in the city of Bengkulu is positive with a total value of (10.289), The results obtained for the consumer behavior towards Surya bakery donut package is positive with a value of (7.5914), which indicates that consumer attitudes $(A B)$, which results either positive or no consistent relationship to consumer behavior (B), which also results in a positive or good.
\end{abstract}

Keywords: Consumer attitude and behaviour, value added, Product development process

\section{PENDAHULUAN}

Proses pengembangan produk hasil pertanian merupakan rekayasa dari perkembangan agribisnis. Menurut Saragih (2000), agribisnis terdiri dari lima subsistem yaitu 1) subsistem agribisnis hulu (up-stream agribussiness) yakni kegiatan industri dan perdagangan yang menghasilkan sarana produksi usaha tani seperti pembibitan, agrokimia, agrootomotif, agriequipment, 2) subsistem usahatani (on farm agribussiness) 3) subsistem agribisnis hilir, dan 4) subsistem pemasaran, dan 5) subsistem jasa penunjang. Salah satu bentuk industri pengolahan hasil pertanian adalah donat. Donat (doughnuts atau donut) adalah penganan yang digoreng, dibuat dari bahan utama nya yaitu tepung terigu, gula, telur dan mentega. Perusahaan roti merupakan salah satu usaha yang bergerak dalam bidang pemenuhan kebutuhan dan sebagai salah satu contoh 
nyata pengembangan produk dari hasil-hasil pertanian, yang juga mengalami persaingan yang sangat ketat dari waktu ke waktu. Perusahaan roti selain sebagai alternatif bagi individu yang tidak mempunyai waktu untuk menyiapkan makanan, juga dapat sebagai media pertemuan formal.

Perusahaan Surya bakery merupakan salah satu perusahaan yang bergerak dalam bidang pemenuhan kebutuhan dan mengembangkan produk dari hasil pertanian, yang menghasilkan produk donat berkualitas dengan harga yang sangat terjangkau. Dengan kemampuan memberikan hasil yang berkualitas baik dari segi rasa, bentuk, dan variasi produk donat dengan kesesuaian antara harga yang diinginkan konsumen, maka dengan penetapan harga yang murah dan kualitas yang tetap diutamakan, membuat perusahaan roti surya mampu untuk bertahan dipasar.

Penelitian ini bertujuan (1) Untuk mengetahui sikap konsumen terhadap pembelian produk donat paket Surya bakery (2) Untuk mengetahui faktor yang mempengaruhi perilaku konsumen, (3) Untuk mengetahui perilaku konsumen dalam mengambil keputusan pembelian donat paket Surya Bakery.

\section{METODE PENELITIAN}

\section{Pengumpulan Data}

Penentuan lokasi penelitian dilakukan di Kota Bengkulu, dengan pertimbangan bahwa masyarakat Bengkulu merupakan konsumen produk donat paket dari perusahaan Surya bakery yang merupakan perusahaan roti yang besar omset penjualannya dan terkenal di Kota Bengkulu. Data yang digunakan adalah data primer dan tata sekunder. Pengambilan responden dilakukan dengan cara accidental sampling. Populasi dalam penelitian ini dimana responden merupakan konsumen yang mempunyai keputusan membeli dan pernah mengkonsumsi produk donat paket Surya bakery minimal 2 kali yang ditemui oleh peneliti yang berjumlah 96 orang.

\section{Analisis Data}

Untuk mengetahui sikap dan perilaku konsumen menggunakan metode Fishbein, Model ini digunakan untuk mengetahui sikap konsumen terhadap keseluruhan atribut produk yang meliputi Varian produk, rasa, warna, harga, kemasan dan label produk (Sumarwan, 2000)

$$
\mathrm{A}_{\mathrm{B}}=\sum_{i=1}^{n}(b i)(e i)
$$

dimana $A_{в}$ adalah sikap total konsumen terhadap produk donat paket Surya bakery di Kota Bengkulu, $b_{i}$ adalah kekuatan keyakinan konsumen terhadap atribut ke-i, $e_{i}$ adalah evaluasi kepercayaan individu terhadap atribut ke-i, n adalah jumlah atribut yang relevan. 
Untuk mengetahui sikap konsumen terhadap produk donat paket Surya bakery di Kota Bengkulu ( $\mathrm{A}_{\mathrm{B}}$ ) digunakan skala dari 2, 1, 0, -1, -2 dengan kriteria sebagai berikut : sangat setuju (2), setuju (1), netral (0), tidak setuju (-1), sangat tidak setuju (-2). Sikap total konsumen terhadap donat paket Surya bakery di Kota Bengkulu dapat ditentukan sebagai berikut (a) jika $\mathrm{A}_{B}<0$, maka nilai sikap total konsumen negative, (b) jika $A_{B}>0$ maka nilai sikap total konsumen positif, dan (c) jika $A_{B}=0$ maka nilai sikap total konsumen tetap

Untuk mengetahui atau memperoleh kosistensi antara sikap dan perilaku maka digunakan model maksud perilaku Fishbein :

$$
B \approx B_{I}=W_{1}\left(A_{B}\right)+W_{2}(S N)
$$

dimana B adalah Perilaku konsumen, $\mathrm{B}_{\mathrm{I}}$ adalah Maksud perilaku, $\mathrm{A}_{\mathrm{B}}$ adalah Sikap konsumen terhadap produk donat Surya Bakery, SN adalah Norma subjektif, $\mathrm{W}_{1}, \mathrm{~W}_{2}$ adalah Bobot yang akan ditentukan yang menggambarkan pengaruh relatif dari komponen. Jika B $>0$ artinya perilaku konsumen loyal terhadap produk donat paket Surya bakery, dan jika $\mathrm{B} \leq 0$ artinya perilaku konsumen tidak loyal terhadap produk donat paket Surya bakery

Cara mencari nilai $\mathrm{SN}$ di dapat dengan rumus :

$$
S N=\sum_{j=1}^{n}\left(N B_{j}\right)\left(M C_{j}\right)^{2}
$$

\section{HASIL DAN PEMBAHASAN}

\section{Analisis Nilai Sikap}

Sikap total konsumen menurut Fishbein adalah perkalian antara nilai atribut keyakinan (bi) dan nilai atribut evaluasi (ei), seperti yang disajikan pada Tabel 1. Dari tabel ini, nilai sikap konsumen pada tiap-tiap atribut memiliki nilai yang sangat beragam. Nilai sikap konsumen dari yang paling tinggi terletak pada atribut warna, yaitu sebesar $(2,968)$. Menurut Staton dan Johanes (1988) dalam Surjadi (2002) bahwa konsumen memiliki keinginan dinamis, dimana mereka membeli produk tidak hanya untuk fungsinya tetapi juga dengan maknanya untuk suatu keputusan yang diinginkan. Selanjutnya pada atribut rasa sebesar $(2,72)$, atribut varian produk sebesar (1.857), atribut harga (1.195), dan atribut kemasan (0.806) sedangkan nilai terendah pada atribut label produk, yaitu sebesar (0.743).

Nilai sikap konsumen pada tiap atribut yang beragam menggambarkan adanya perbedaan keyakinan konsumen terhadap beberapa atribut (bi) dengan kondisi kenyataan di lapangan (ei). Nilai total sikap konsumen terhadap produk donat paket Surya bakery di Kota Bengkulu $(\mathrm{AB})=10.289>0$, hal ini menunjukkan bahwa, konsumen donat paket Surya bakery memiliki sikap yang positif terhadap atribut-atribut yang ditawarkan perusahaan Surya bakery. Untuk mengetahui sikap total konsumen ini berada pada skala penilaian yang mana, maka perlu dihitung berapa nilai maksimum dan minimum untuk sikap. 
Skala sikap ini dilihat dari hasil perkalian variabel atribut evaluasi dikalikan dengan skor-skor penilaian konsumen dari yang paling positif hingga paling negatif.

Tabel 1 Nilai Sikap Total Konsumen Terhadap Produk Donat Surya Bakery di Kota Bengkulu

\begin{tabular}{llccc}
\hline No & \multicolumn{1}{c}{ ATRIBUT } & $\begin{array}{c}\text { Nilai } \\
\text { Keyakinan } \\
(\mathrm{bi})\end{array}$ & $\begin{array}{c}\text { Nilai } \\
\text { Evaluasi (ei) }\end{array}$ & $\begin{array}{c}\text { Nilai Total } \\
\mathrm{A}_{\mathrm{B}}=(\mathrm{bi}) \times(\mathrm{ei})\end{array}$ \\
\hline 1 & Varian Produk & 1.166 & 1.593 & 1.857 \\
2 & Harga & 1.0625 & 1.125 & 1.195 \\
3 & Rasa & 1.5833 & 1.718 & 2.72 \\
4 & Warna & 1.677 & 1.77 & 2.968 \\
5 & Kemasan & 0.8333 & 0.968 & 0.806 \\
6 & Label Produk & 0.927 & 0.802 & 0.743 \\
\hline \multicolumn{2}{c}{ JUMLAH } & & 10.289 \\
\hline
\end{tabular}

Sumber: Data primer diolah, 2012

Rentang skor 2 = sangat baik ke skor $-2=$ sangat tidak baik, sehingga berdasarkan perhitungan diatas, maka didapat nilai skor tentang sikap konsumen terhadap produk donat Surya bakery adalah sebagai berikut :

STB

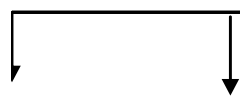

$-15.952-9571,2$
Tidak Baik
Netral

Baik

Sangat baik

Gambar 1. Skala sikap konsumen terhadap paket donat Surya bakery

Berdasarkan skala diatas maka nilai sikap total konsumen terhadap paket donat Surya bakery di Kota Bengkulu berada antara 9571,2 - 15.952 yang berarti nilai sikap total konsumen berada pada kategori baik. Secara keseluruhan konsumen setuju dengan atribut-atribut yang ditawarkan oleh paket donat Surya bakery di Kota Bengkulu.

Hasil penelitian ini sesuai dengan hasil penelitian Efli Awal (2003) yang menyatakan sikap yang positif yang ditunjukkan responden terhadap pengecer pestisida di Kecamatan Manna Bengkulu Selatan menunjukkan pengecer pestisida tersebut memiliki citra yang baik dimata responden. Penelitian ini juga sependapat dengan penelitian Afrizal (2002) yang menyatakan nilai sikap total konsumen berada pada nilai agak baik, yang mengidentifikasikan bahwa konsumen setuju dengan berbagai atribut yang ditawarkan Lempuk Yovita. 
Tabel 2 Nilai Norma Subjektif

\begin{tabular}{clccc}
\hline No & Variabel & $\begin{array}{c}\text { Motivasi } \\
(\mathrm{MCj})\end{array}$ & $\begin{array}{c}\text { Keyakinan } \\
\text { Normatif } \\
(\mathrm{NBj})\end{array}$ & $\begin{array}{c}\text { Norma Subjektif } \\
(\mathrm{SN}=(\mathrm{NBj}) \times(\mathrm{MCj})\end{array}$ \\
\hline 1 & Anggota Keluarga & 1.4375 & 1,333 & 1.9161 \\
2 & Orang Lain & 0,6875 & 0,5937 & 0,4081 \\
3 & Teman & 1.0625 & 1,104 & 1.173 \\
4 & Tenaga Penjual & -0.2708 & -0.177 & 0,04793 \\
\hline & JUMLAH & & & 3.54513 \\
\hline
\end{tabular}

Sumber : Data diolah, 2012

Perilaku (B) adalah tindakan yang dilakukan seseorang yang dipengaruhi oleh nilai total Sikap $\left(\mathrm{A}_{\mathrm{B}}\right)$, dan nilai total Norma Subjektif $(\mathrm{SN})$. Maksudnya adalah perilaku terbentuk akibat adanya gabungan antara sikap yang merupakan faktor internal individu (konsumen) dan norma subjektif yang merupakan faktor eksternal individu. Nilai perhitungan perilaku konsumen hasil perkalian nilai sikap total $\left(\mathrm{A}_{\mathrm{B}}\right)$ dengan konstanta $(\mathrm{w} 1)$ dan dijumlahkan dengan nilai total Norma Subjektif (SN) yang juga dikalikan dengan konstanta (w2). Dimana nilai $w 1=0,6$ dan $w 2=0,4$ diambil berdasarkan hasil penelitian empiris Della Bitta di dalam Umar, H (1998).

Hasil nilai perilaku konsumen didapat sebagai berikut :

$$
\begin{aligned}
\mathrm{B} \approx \mathrm{BI} & =\mathrm{W}_{1}(\mathrm{AB})+\mathrm{W}_{2}(\mathrm{SN}) \\
& =0.6(10,289)+0.4(3.54513) \\
& =6.1734+1.418052 \\
& =7.5914
\end{aligned}
$$

Hasil nilai analisis perilaku konsumen donat paket Surya bakery di Kota Bengkulu menghasilkan nilai $\mathrm{B}($ perilaku $)=7.5914$ dimana nilai $\mathrm{B}=7.5914>0$ menunjukkan bahwa perilaku konsumen positif, artinya perilaku konsumen terhadap donat paket Surya bakery juga baik/ loyal. Menurut Umar (1998), jika nilai B positif (lebih besar dari nol) maka tanggapan konsumen adalah baik. Ini mengidentifikasikan bahwa sikap konsumen $\left(\mathrm{A}_{B}\right)$ yang hasilnya positif atau baik ada hubungan yang konsisten dengan perilaku konsumen (B) yang juga menghasilkan nilai positif/baik. Hal ini sesuai dengan pendapat Nugroho (2003) bahwa sikap yang positif terhadap merek tertentu akan memungkinkan konsumen melakukan pembelian terhadap merek itu. Sebaliknya sikap negative akan menghalangi konsumen untuk melakukan pembelian. Seperti yang dikatakan salah satu responden yang bernama Nadya Ayudiah Putri mengatakan bahwa, jika atribut-atribut sesuai dengan harapan konsumen, maka akan menyebabkan konsumen loyal terhadap produk donat paket tersebut dan 
akan melakukan pembelian berulang. Karena konsumen merasa apa yang diinginkan dari keseluruhan atribut produk sudah terpenuhi. Selanjutnya Shiffman dan Kanuk (1997) dalam Afrizal (2002) juga berpendapat bahwa suatu ukuran sikap berpengaruh ekuivalen terhadap perilaku, jika tidak ada factor lain yang diteliti. Umar (1998) juga menyatakan bahwa sikap yang positif dari konsumen akan diikuti oleh perilaku yang positif. Penelitian ini setara dengan hasil penelitian Afrizal (2003) yang menyatakan bahwa sikap konsumen ada hubungan yang konsisten dengan perilaku konsumen. Penelitian ini juga sependapat dengan hasil penelitian Mukhlis (2003) yang menyatakan bahwa sikap mencerminkan perilaku petani (konsumen ) itu sendiri . Tetapi hasil penelitian ini bertolak belakang dengan penelitian Betharia (2001) yang menyatakan tidak ada hubungan antara sikap dan perilaku konsumen terhadap makanan siap saji (fast food) california fried chicken di Kota Bengkulu, artinya sikap yang positif tidak diikuti dengan perilaku yang positif dari konsumen.

\section{SIMPULAN DAN SARAN}

\section{Simpulan}

Berdasarkan hasil penelitian yang dilakukan tentang "Sikap dan Perilaku Konsumen Terhadap Donat Paket Surya Bakery di Kota Bengkulu", maka dapat diambil suatu kesimpulan sebagai berikut :

1. Secara keseluruhan Sikap total konsumen $\left(\mathrm{A}_{\mathrm{B}}\right)$ terhadap produk paket donat Surya bakery di Kota Bengkulu bernilai positif dengan nilai total sebesar $(10,289)$, yang berarti nilai sikap total konsumen berada pada niali baik. Yang mengidentifikasikan bahwa sebagian besar konsumen setuju dengan berbagai atribut yang ditawarkan paket donat Surya bakery. Atribut yang ditawarkan bernilai positif adalah varian produk. harga, rasa,dan warna, sedangkan atribut kemasan dan label produk cenderung negative dikarenakan kurang lengkapnya informasi yang terdapat pada label dan kemasan paket donat Surya bakery.

2. Perilaku konsumen dipengaruhi oleh dua factor yaitu Sikap total konsumen $\left(A_{B}\right)$ dan Norma Subjektif (SN). Hasil yang diperoleh untuk perilaku konsumen terhadap paket donat Surya bakery bernilai positif dengan nilai sebesar (7.5914) yang mengidentifikasikan bahwa sikap konsumen $\left(\mathrm{A}_{\mathrm{B}}\right)$ yang hasilnya positif atau baik ada hubungan yang konsisten dengan perilaku konsumen (B) yang juga menghasilkan nilai positif atau baik.

3. Pada Norma Subjektif (SN) yang berpengaruh pembelian paket donat Surya bakery adalah dari atribut anggota keluarga dengan nilai sebesar $(1,9161)$, artinya konsumen donat paket Surya bakery merasa yakin dalam pembelian donat Surya bakery ia merasa termotivasi atau dipengaruhi anggota keluarganya. 


\section{Saran}

Pihak perusahaan perlu meningkatkan kualitas dan kuantitas terhadap atribut-atribut yang ditawarkan paket donat Surya bakery berdasarkan prioritas yaitu varian produk, harga, rasa, warna, label produk dan kemasan, meskipun hasil dari beberapa atribut bernilai positif, akan tetapi ada dua atribut yang menjadi dua prioritas utama yang harus dilakukan evaluasi agar keinginan konsumen lebih terpenuhi, seperti lengkap nya informasi (label produk) mengenai bahan-bahan baku produk, jenis varian rasa yang tertera di label dan kemasan, tanda produksi, tanggal pembuatan ataupun tanggal kadaluarsa.

Perlu adanya penelitian lebih lanjut tentang sikap dan perilaku konsumen terhadap paket donat Surya bakery, dengan menambahkan factor lain selain sikap dan norma subjektif atau dengan tehnik dan analisis yang berbeda sehingga hasil yang diperoleh dapat dibandingkan dengan penelitian ini.

\section{DAFTAR PUSTAKA}

Afrizal, 2003. Analisis Sikap dan Perilaku Konsumen Terhadap Makanan Lempuk Yovita di Kota Bengkulu. Skripsi. Jurusan Sosial Ekonomi Pertanian, Fakultas Pertanian, Universitas Bengkulu. (tidak dipublikasikan)

Anwar Prabu, M. 1997. Perilaku Konsumen. Yogyakarta

Betharia. 2001. Analisis Sikap dan Hubungannya dengan Perilaku Konsumen Makanan Siap Saji (Fast Food) California Fried Chicken di Kota Bengkulu. Skripsi. Jurusan Sosial Ekonomi Pertanian, Fakultas Pertanian, Universitas Bengkulu. (tidak dipublikasikan)

Mukhlis. 2003. Analisis Sikap dan Perilaku Petani terhadap Pestisida Agrimec 18 BC PT Syngenta di Desa Sumber Urip Kecamatan Selupu Rejang Kabupaten Rejang Lebong. Skripsi. Jurusan Sosial Ekonomi Pertanian, Fakultas Pertanian, Universitas Bengkulu. (tidak dipublikasikan)

Nugroho, J. Setiadi. 2003. Perilaku Konsumen. Prenada Media, Jakarta.

Saragih, B. 2000. Karakteristik Agribisnis dan Implikasinya untuk Manajemen Agribisnis. Jurnal Agribisnis Vol. 2 No. 2, Januari-Juni 2000. Pusat Bisnis Universitas Jember.

Surjadi. 2002. Pengaruh Iklan terhadap Perilaku Pembelian Konsumen Teh dalam Keluarga. Jurnal Agroekonomi Vol.2 No. 2. Pusat penelitian dan Pengembangan Sosial Ekonomi Pertanian, Bogor.

Umar, H. 1998. Metode Penelitian untuk Skripsi dan Tesis Bisnis. PT rajaGrafindo Persada, Jakarta. 